\title{
Por uma história pública dos africanos escravizados no Brasil
}

For a public history of enslaved Africans in Brazil

Hebe Mattos, Martha Abreu e Milton Guran Autores convidados

O desafio de organizar o Inventário dos Lugares de Memória do Tráfico Atlântico de Escravos e da História dos Africanos Escravizados no Brasil ${ }^{1}$ nos foi proposto em 2011 - ano escolhido pela Unesco como ano internacional dos afrodescendentes - por Milton Guran, então representante no Brasil do Comitê Científico Internacional do Projeto da Unesco Rota do Escravo: Resistência, Herança e Liberdade. Guran também estava como professor visitante no Programa de Pós-Graduação e História da Universidade Federal Fluminense(PPGH/UFF)e tinha um trabalho de parceira com o Laboratório de História Oral e Imagem

Hebe Mattos é professora titular de História do Brasil do Departamento de História da UFF, bolsista do CNPq e cientista do Nosso Estado/Faperj (hebe.mattos@gmail.com).

Martha Abreu é professora associada do Departamento de História da UFF, bolsista do CNPq e cientista do Nosso Estado (marthabreu@terra.com.br).

Milton Guran é antropólogo, professor visitante do Programa de Pós-Graduação em História da UFF e representante do Brasil no Projeto Rota do Escravo da Unesco.

Est. Hist., Rio de Faneiro, vol. 27, no 54, p. 255-273, julho-dezembro de 2014. 
(LABHOI/UFF), onde desenvolvíamos, desde 2005, projetos sobre Memórias da Escravidão nas dimensões da pesquisa acadêmica e da história pública, com a elaboração de DVDs historiográficos e sites de divulgação. Nosso campo de estudos envolvia a pesquisa sobre campesinato, família, cultura e música negra no pós-abolição. ${ }^{2}$ Em diálogo com nosso trabalho de pesquisa sobre Memórias do Cativeiro, já tínhamos também entrado em contato com comunidades quilombolas e jongueiras, que, em nome do "dever de memória", reivindicavam direitos e reparações, propiciando dessa forma nossa participação e mediação na construção de relatórios históricos e antropológicos técnicos para o INCRA (Mattos e Abreu, 2011a: 147-160).

Já tínhamos, portanto, experiência na organização de acervos, na divulgação da pesquisa acadêmica para públicos mais amplos e no assessoramento de demandas sociais e culturais através da pesquisa histórica, ${ }^{3}$ incluindo-se aí fundamentalmente $o$ assessoramento às comunidades negras, que ajudaram a construir o acervo Passados Presentes/Memória do Cativeiro do $\mathrm{LABHOI}^{4} \mathrm{e}$ foram parceiras na produção de nossos filmes e pesquisas (Mattos e Abreu, 2011b). Evidentemente, a organização de um Inventário de Lugares de Memória nos exigiu novas estratégias de pesquisa, seleção e divulgação, como iremos explicar, assim como novas reflexões e abordagens em relação à problemática dos deveres de memória e em relação ao trauma e ao legado da escravidão africana em nosso país.

O Inventário é uma das ações propostas pelo Projeto Rota do Escravo da Unesco. Criado em 1993, por ocasião da $27^{\mathrm{a}}$ Conferência Geral da Unesco (Araujo, 2010, cap.2) o projeto teve importante papel no reconhecimento da escravidão e do tráfico de escravos como "crimes contra a humanidade" na Conferência Mundial contra o Racismo, Discriminação Racial, Xenofobia e Intolerância, realizada em Durban, África do Sul, em 2001. ${ }^{5}$ Enquadrava-se nos esforços pluridisciplinares da Unesco pela cultura da paz, pelo aprofundamento dos valores universais, combate à ignorância e promoção do diálogo intercultural. Entre os objetivos mais importantes do projeto Rota do Escravo, podemos destacar a preocupação de trazer à tona histórias ocultadas, intervir na construção de memórias públicas e sensibilizar variados públicos para a tragédia humana da escravidão e do tráfico.

Ao romper o silêncio sobre a tragédia da escravidão e do tráfico, uma tragédia ainda presente no mundo atual, o projeto Rota do Escravo propõe intervir nas consequências impostas por esses encontros forçados, fonte das interações culturais e diversidade das sociedades que viveram essas histórias e se transformaram hoje em sociedades multiétnicas e multiculturais. Três princípios básicos - Resistência, Liberdade e Herança - nos nortearam na construção do Inventário. Desde 2012, os três princípios fazem parte do próprio título do projeto, por 
decisão de seu comitê científico. Com a ideia de resistência procura-se evidenciar como as vítimas da escravatura jamais cessaram de resistir; com a noção de liberdade, observa-se que a luta contra a escravidão redefiniu as próprias noções de liberdade, de dignidade e de humanidade como direitos universais; pela herança valoriza-se o patrimônio cultural criado pela diáspora no chamado Novo Mundo e presente em nosso tempo.

Entre as diversas ações propostas e realizadas pelo projeto Rota do Escra$v o$ encontram-se o apoio à produção de trabalhos científicos, o desenvolvimento de materiais pedagógicos para o ensino da história da escravidão e do tráfico de escravos, a elaboração de atlas das interações e das diásporas africanas, a criação de novas formas de representação da escravatura nos museus, a organização de eventos, festivais e exposições que valorizem heranças culturais comuns, a coleta e preservação de arquivos e tradições orais, a produção e divulgação de materiais de informação e sensibilização (como filmes e clipes), a escolha de datas e anos comemorativos, como o ano de 2004 (200 anos da Revolução do Haiti) para a comemoração da luta contra a escravatura e de sua abolição e o de 2011 para ano internacional afrodescendente, e a própria iniciativa do Inventário dos sítios e lugares de memória. Um balanço das iniciativas neste sentido foi feito em conferência internacional realizada no Brasil, com organização da Fundação Palmares, na qual apresentamos pela primeira vez os resultados do trabalho realizado. ${ }^{6}$

A proposta de construção do Inventário envolveu-se diretamente com a identificação e a divulgação dos locais de memória da escravidão africana e do tráfico de escravos para o Brasil. Até finais do século XX, impressiona a ausência de esforço para determinar os lugares de memória dos processos de escravização em massa, que estão na origem do mundo contemporâneo. $O$ tráfico de escravos revelou-se tema tabu na memória da maioria dos países envolvidos, na Europa, nas Américas e na África, bem como no Oceano Índico. No livro clássico de Pierre Nora, o historiador francês que consagrou a expressão "lugar de memória" (Les Lieux de Mémoire) ao trabalhar com a memória nacional e republicana na França, a escravidão como objeto de memória está simplesmente ausente, ainda que o país tenha tido participação importante no processo e tenha parte expressiva de seus cidadãos formada hoje por descendentes de africanos escravizados em antigas colônias que escolheram permanecer como departamentos franceses.

Mesmo que os aspectos culturais da diáspora africana tenham merecido atenção desde muito cedo no continente americano, os mecanismos do tráfico propriamente dito, ou seja, aqueles que possibilitaram os processos massificados de escravização permaneceram praticamente ignorados na memória pública. Este silêncio estava diretamente relacionado a um duplo processo. Por um lado, o combate e a deslegitimação do tráfico negreiro no mundo ocidental, desde finais do século XVIII, trouxeram desonra às atividades negreiras, que entretanto continua- 
ram a se desenvolver em escala impressionante até tardiamente no século XIX. Por outro, as dimensões de vergonha e desonra, ligadas tradicionalmente à experiência da escravização nas sociedades escravocratas, tenderam a produzir o silêncio e a discriminação aberta como formas históricas de conviver com a incorporação dos ex-escravos nas antigas sociedades escravistas. Podemos afirmar, mesmo sem discorrer mais longamente sobre o processo, que o combate ao racismo como forma institucionalizada de discriminação levou ao questionamento do silêncio sobre a violência da escravização como forma velada de expressão do racismo. Durban, 2011, foi um momento de inflexão neste movimento.

O Projeto Rota do Escravo teve importante papel nesta quebra do silêncio em torno das formas históricas que possibilitaram que a tragédia do tráfico negreiro se produzisse com as dimensões que a caracterizaram, com resultados significativos como a construção de museus sobre o tema em cidades como Liverpool, Bordeaux e Nantes, e a ampliação do conhecimento e do aprendizado sobre o tráfico e a escravização de africanos por meio da criação de itinerários de visitação e da consolidação do turismo cultural e de memória, como os que já foram feitos em Cuba, Haiti, Argentina, Uruguai e Paraguai e em diversos países da África (Pineau, 2012).

Ao lidar com um passado sensível, que envolve, por exemplo, as responsabilidades no tráfico negreiro das modernas democracias ocidentais, bem como das elites africanas pré-coloniais, além de temas como a dor e a vergonha vivenciada pelos escravizados, a memória da diáspora africana, resultante do tráfico negreiro, elabora tais temáticas na memória pública. Ao mesmo tempo, não abandona a grandeza dos legados culturais da globalização forçada, resultado da resistência dos escravizados, e seu papel para as definições contemporâneas de liberdade e direitos humanos com as quais trabalhamos.

A estratégia de dar visibilidade a estes temas através da visitação dos locais de memória não só consolidava novas formas de rememoração, para públicos que desconheciam ou se recusavam a falar desse passado, mas também abria caminhos de sustentabilidade para os grupos que sofriam o peso do estigma de serem descendentes dos antigos escravizados. Por uma feliz coincidência, quando a proposta de realizar o Inventário chegou até nós, através de Milton Guran, acompanhávamos de perto a luta pelo reconhecimento de comunidades quilombolas e jongueiras do Rio de Janeiro e Sudeste, que encontravam na visibilidade de sua própria história e identidade um efetivo caminho de luta e reparação. ${ }^{7}$

Por outro lado, o fim do silêncio sobre a ilegalidade do tráfico de africanos no Brasil na primeira metade do século XIX estava sendo exposto e denunciado por historiadores da escravidão como Sidney Chalhoub (2012) e Luiz Felipe Alencastro e por uma série de pesquisas por nós orientadas na Universidade 
Federal Fluminense (Mattos, 2013). ${ }^{8}$ Tais trabalhos se originaram da tradição oral de lideranças quilombolas do Bracuí e da região de Cabo Frio e Búzios, no Rio de Janeiro, sobre o tráfico ilegal nas terras onde moraram e trabalharam seus antepassados africanos e escravizados. Nem todos tinham esquecido ou feito questão de esquecer o tráfico ilegal de africanos. As pesquisas históricas sobre o tráfico ilegal cresciam também em todo o Brasil. Beatriz Mamigonian (2007) e Marcus Carvalho (2009: 151-167) concluíam trabalhos acadêmicos importantes sobre o tráfico ilegal no sul do Brasil e em Pernambuco.

Memória e História se encontravam no século XXI para denunciar a ilegalidade do tráfico e, consequentemente, da própria escravização de mais de 760 mil africanos e seus descendentes chegados a partir da lei que proibia o tráfico, de 1831, e mantidos escravizados até 1888. Luiz Felipe Alencastro usaria esse argumento como um dos mais legítimos e eficazes para justificar as ações afirmativas e as cotas para negros nas universidades no debate realizado pelo Supremo Tribunal Federal em 2010. O Estado Imperial no Brasil havia viabilizado um pacto de esquecimento e violação da lei de 1831. Como salienta o historiador, "moralmente ilegítima, a escravidão do Império era ainda - primeiro e sobretudo - ilegal" (Alencastro, 2010: 3).

O convite para realizar o Inventário vinha mesmo em boa hora. Acompanhávamos de perto a emergência de comunidades de descendentes de africanos e a publicização de suas histórias em lutas que travavam, acionando a memória da escravização, do tráfico e do patrimônio construído na diáspora. Dialogávamos com historiadores da escravidão que, como nós, com suas pesquisas acadêmicas, dialogavam diretamente com as pautas sociais contemporâneas. A escravidão era mais que nunca, no Brasil de inícios do século XXI, um passado ainda presente. O Inventário traria a oportunidade de tornar público, de uma forma mais organizada e sistematizada, um conhecimento histórico que poderia enriquecer e abrir novas perspectivas para políticas memoriais e de implementação do turismo cultural em relação à memória da escravidão.

Para além da divulgação científica, a história da escravidão e do tráfico, ao se tornar pública, possibilitava também reparação moral, reforço da autoestima e construção de sustentabilidade econômica para os detentores de todas essas histórias e patrimônios. O Inventário poderia se tornar ferramenta de luta para as comunidades negras presentes nos locais de memória identificados ou herdeiras de seu patrimônio e legado - e, certamente, iria trazer novos caminhos e mais desafios às nossas pesquisas acadêmicas.

Bem, mas isso era só o começo, ou ao menos as razões que nos motivaram a aceitar o trabalho e seguir em frente com o desafio. $O$ primeiro movimento para a construção do Inventário foi a abertura de uma consulta pública, em página do LABHOI, convidando os interessados a indicar os locais de memória do tráfico e da escravização de africanos de que tinham conhecimento ou referência. A 
estratégia foi completamente infrutífera, provavelmente em decorrência da pequena divulgação.

Em função dos prazos, partimos para a consulta direta, através de e-mails, a especialistas nos estudos de escravidão de todo o Brasil. A resposta foi animadora e promissora. Formamos uma respeitável rede de colaboradores, entre professores reconhecidos, jovens mestrandos e doutorandos das diversas instituições de pesquisa do país, que contribuiu, ao longo de 2012, para o trabalho de indicação, seleção e redação dos verbetes de cada local de memória. Sem a contribuição de diversos historiadores, antropólogos e geógrafos do país, após consultas e intensas trocas de informações, inclusive na indicação de bibliografia ou fontes de referência, não teria sido possível a reunião de tão amplo e variado material. $O$ trabalho coletivo de diversos especialistas transformou o Inventário numa espécie de acervo da história dos africanos no Brasil, ao mesmo tempo em que indicou novas possibilidades de pesquisa e divulgação dessa história. ${ }^{9}$

Além da disposição dos pesquisadores, é importante destacar que a reunião de 100 locais de memória, com referências precisas, documentais e bibliográficas, revela o avanço da pesquisa histórica sobre o tráfico e a escravização de africanos em nosso país. A decisão de inventariar 100 locais foi até certo ponto arbitrária, já que era um número redondo e significativo, mas também correspondeu às possibilidades da rede de pesquisadores que foi possível formar naquele momento. Temos a certeza de que estamos longe de esgotar o Inventário. Nosso trabalho deve ser entendido como um ponto de partida para novas e futuras ações (nos âmbitos federal, estadual e municipal), tanto no campo da pesquisa histórica como nos do ensino, educação patrimonial, divulgação e desenvolvimento do turismo cultural dos Lugares de Memória do Tráfico e História dos Africanos Escravizados no Brasil.

Demos prioridade às evidências documentais, escritas ou orais, da presença histórica e cultural dos africanos, com o objetivo de centrar o foco na ação e no legado dos recém-chegados. Por outro lado, sabemos que a lista seria interminável se tivéssemos optado por reunir os Lugares de Memória dos descendentes de africanos no Brasil. O inventário é sobre os locais onde é possível lembrar a chegada dos africanos de primeira geração ou identificar as marcas de sua presença e intervenção.

Escravizados em seu continente entre os séculos XVI e XIX, muitas vezes em guerras internas entre os inúmeros reinos que existiam nas diversas regiões da África tocadas pelo tráfico, africanos de diferentes línguas e origens tornaram-se "escravos", categoria jurídica de época, no Brasil. Aqui reorganizaram suas identidades, criando novos sentidos para suas referências africanas. Nos verbetes, utilizamos tanto o termo jurídico de época (escravo) quanto o adjetivo "escravizado", que sublinha o caráter compulsório da instituição. Para referir as novas identidades africanas criadas nas Américas, respeitamos a diversidade de 
expressões utilizadas pelos especialistas consultados, refletindo diferentes cronologias, abordagens historiográficas e usos regionais.

Se, de início, foi uma tarefa difícil a separação entre africanos e afrodescendentes, o esforço foi recompensado. Conseguimos centrar o foco nos africanos escravizados e, a partir da reunião do vasto material, evidenciar as impressionantes dimensões de suas ações no Brasil. Nem todas elas já eram previamente conhecidas do conjunto de especialistas no tema. O Inventário também permitiria o aprofundamento da pesquisa acadêmica.

Para melhor compreensão e maior visibilidade dos Lugares de Memória do Tráfico Atlântico de Escravos e da História dos Africanos, organizamos os 100 Lugares em 7 diferentes temáticas que dizem respeito aos locais de entrada e campos de atuação dos africanos no Brasil: portos de chegada, locais de quarentena e venda; desembarque ilegal; casas, terreiros e candomblés; igrejas e irmandades; trabalho e cotidiano; revoltas e quilombos; patrimônio imaterial. Na seleção dos lugares de memória, priorizamos locais com patrimônio material visível, locais de referência do patrimônio imaterial - as culturas vivas em suas diferentes manifestações - e locais onde apenas podemos imaginar o que se passou ou o que foi vivido pelos africanos a partir das narrativas dos historiadores, já que não há mais vestígios visíveis e materiais. ${ }^{10}$

Em relação aos portos de chegada, locais de quarentena e venda, selecionamos 9 indicações: Cafua das Mercês (São Luís - Maranhão), Rua do Bom Jesus (Recife - Pernambuco), Cais da Cidade Baixa (Salvador - Bahia), Porto de São Mateus (São Mateus - Espírito Santo), Cais do Valongo (Rio de Janeiro-RJ), Cemitério dos Pretos Novos (Rio de Janeiro - RJ), Mercado do Valongo (Rio de Janeiro - RJ), Ilha do Bom Jesus (Ilha do Fundão/Rio de Janeiro - RJ) e Porto Jaguarão (Jaguarão - Rio Grande do Sul).

A execução do tráfico atlântico de africanos escravizados envolveu a construção de portos, locais de quarentena e venda de africanos recém-chegados nas diversas cidades portuárias ao longo do período colonial. A partir do final do século XVIII, o comércio negreiro começou a perder legitimidade no mundo Atlântico, até tornar-se ilegal na maioria dos países que o praticavam, no início do século XIX. Em 7 de novembro de 1831, o governo imperial brasileiro promulgou a primeira lei proibindo a entrada de escravos africanos no país, prevendo pesadas penas para quem vendesse, transportasse ou comprasse africanos traficados em território brasileiro.

Entretanto, até a lei de 1850, as autoridades toleraram os horrores do tráfico. Mesmo com o tráfico condenado internacionalmente, mais de 750 mil pessoas foram contrabandeadas para o Brasil. Por outro lado, ao descumprirem a lei de 1831, os comerciantes de africanos tiveram que buscar maior discrição para seus negócios e buscaram locais de desembarque afastados dos centros urbanos. 
Em 4 de setembro de 1850, finalmente, uma nova lei, conhecida como Lei Euzébio de Queiroz, foi aprovada no Parlamento. Após sua promulgação, apesar da continuidade do contrabando, a repressão ao tráfico avançou significativamente até sua completa extinção.

Entre as 9 indicações nesta temática, a do cais do Valango ganhou grande visibilidade pelas recentes descobertas arqueológicas na área central da cidade do Rio de Janeiro. No verbete do historiador Claudio Honorato, registramos que, em 1774, o Vice-Rei Marquês do Lavradio determinou que o comércio de africanos passasse a ficar "fora dos limites da cidade" do Rio de Janeiro. O novo local escolhido para esse comércio foi o Valongo, entre a Pedra do Sal e a Gamboa. Com propósito de não contaminar a cidade, a ideia era isolar os recém-chegados, que ali esperariam a venda para depois saírem diretamente pelo mar, através do Cais do Valongo e de outros trapiches próximos. Estima-se que passaram pela região quase 1 milhão de africanos. A partir de 1831, com a proibição do tráfico de africanos pelo Governo Imperial, a entrada de escravos pelo Valongo diminuiu significativamente, e os comerciantes tiveram que buscar maior discrição no comércio de africanos. Procuraram locais mais seguros para o tráfico, em geral em praias isoladas, mas não muito distantes dos polos dinâmicos da economia brasileira, como as regiões cafeeiras do Sudeste, que requisitavam mão de obra escrava africana. A principal referência bibliográfica para o verbete foi a dissertação de mestrado de Claudio de Paula Honorato: "Valongo: o mercado de escravos do Rio de Janeiro, 1758 a 1831" (Honorato, 2008).

Sobre os locais de desembarque ilegal, importante novidade da pesquisa acadêmica no Inventário, foram feitas 15 indicações: Barra da Catuama (Goiana PE), Ilha de Itamaracá (Itamaracá - PE), Praia de Porto de Galinhas (Ipojuca PE), Baía de Camanu (Camamu - BA), Ilha de Itaparica (Pontinha/Vera Cruz BA), Praias de Manguinhos e Buena (São Francisco de Itabapoana - RJ), Praias José Gonçalves e Rasa (Búzios - RJ), Catedral do Santíssimo (Campos dos Goytacazes - RJ), Ilha da Marambaia (Mangaratiba - RJ), Bracuí (Angra dos Reis RJ), Sítio Arqueológico São Francisco (São Sebastião - SP), Ilha do Bom Abrigo (Cananéia - SP), Fortaleza da Ilha do Mel (Paranaguá - PR), Ilha Campeche e Armação da Lagoinha (Florianópolis - SC), Praia do Barco (Capão da Canoa RS).

Apesar da existência da lei de 1831, há muitas notícias sobre desembarques ilegais de africanos ao longo da costa brasileira nas décadas de 1830 e 1840, em regiões distantes dos centros urbanos e mais protegidas da observação pública. Mesmo após a lei de 1850, há registros de contrabando de africanos em diversos locais do litoral brasileiro. Os desembarques ilegais, em geral em praias pouco frequentadas, contavam com a tolerância das autoridades e com o apoio dos fazendeiros de áreas próximas do litoral e da população local. 
Uma das mais expressivas descrições desses desembarques encontra-se no verbete, sugerido por Marcus Carvalho, sobre a Barra da Catuama, Goiana, em Pernambuco. Em 17 de abril de 1837, o Diário de Pernambuco publicou uma carta defendendo o tráfico de escravos, apesar do comércio de africanos ter sido proibido pelo governo imperial em 7 de novembro de 1831. Notícias sobre o desembarque ilegal de africanos pelo litoral de Pernambuco espalharam-se rapidamente e atraíram compradores de Alagoas, Paraíba e Rio Grande do Norte. Alguns engenhos, localizados próximo ao litoral, foram utilizados como mercados de escravos. Dentro desse contexto, Barra de Catuama, próxima de Itamaracá e não muito distante de Recife, destacava-se como um dos pontos favoritos para o desembarque clandestino de africanos. A referência bibliográfica é do próprio Marcus Carvalho em "A repressão do tráfico atlântico de escravos e a disputa partidária nas províncias: os ataques aos desembarques em Pernambuco durante o governo praieiro, 1845-1848" (Carvalho, 2009: 151-167).

No campo religioso afro-brasileiro - as casas, terreiros e candomblés - encontram-se as referências mais conhecidas da presença de africanos no Brasil. Entretanto, surpreende a antiguidade de alguns desses centros religiosos, sua duração no tempo e a autonomia de seus fundadores: Casa das Minas (São Luís-MA), Terreiro do Pai Adão (Recife-PE), Casa de Tio Herculano (Laranjeiras - SE), Terreiro da Casa Branca do Engenho Velho - Ilê Axé Iyá Nassô Oká (Salvador - BA), Terreiro do Alaketu - Ilê Maroiá Laji (Salvador - BA), Terreiro do Gantois - Ilê Iyá Omi Axé Iyamassê (Salvador - BA), Terreiro do Bogum - Zoogodô Bogum Malê Hundó (Salvador - BA), Roça do Ventura - Zoogodô Bogum Malê Seja Hundé (Cachoeira - BA), Candomblé do Capivari (São Félix - BA), Ilê Axé Opô Afonjá (Rio de Janeiro e Salvador-RJ e BA) e Pedra do Sal (Rio de Janeiro-RJ).

A presença das religiões africanas no Brasil pode ser identificada em fontes históricas desde o início da colonização. Procedentes principalmente da África Ocidental, atuais Nigéria e Benin, ou Central, atuais Angola, Congo e Moçambique, os recém-chegados procuraram recriar seu patrimônio cultural e religioso diante das novas condições de vida. Centros religiosos fundados ao longo do século XIX podem ser atualmente encontrados, evidenciando a impressionante vitalidade da tradição oral e das formas de organização religiosa dos povos africanos no Brasil. Entre os locais registrados no Inventário, são representativos a Casa de Tio Herculano, em Laranjeiras, Sergipe, e o Candomblé do Capivari, em São Feliz, Bahia.

Sobre Tio Herculano, embora tenha chegado a Laranjeiras na condição de escravizado, não se sabe ao certo quando conseguiu a liberdade. Ao falecer na mesma cidade em 1907, revelou, através de seu inventário, que havia conseguido adquirir algumas posses. Entre elas destacava-se a casa que era sede do terreiro nagô que então dirigia, na rua Comandaroba. Nos documentos oficiais, Hercula- 
no aparecia como Herculano da Costa ou Herculano Barbosa, provável nome de família de seu antigo senhor. Herculano foi casado com Bernarda, com quem teve 8 filhos. Seus descendentes até hoje se encarregam da guarda dos santos. A Casa foi restaurada pelo Instituto do Patrimônio Histórico e Artístico Nacional (IPHAN) em 2011. O verbete foi indicado e produzido por Beatriz Góis Dantas, e a melhor referência é seu próprio livro Vovó Nagô e Papai Branco: usos e abusos da África no Brasil (Dantas, 1988).

O Candomblé do Capivari localiza-se a cerca de $6 \mathrm{~km}$ da cidade de São Félix, na margem direita do riacho Capivari, logo após a entrada do antigo Engenho de Nossa Senhora da Natividade da Fazenda Capivari. Foi fundado pelo africano Anacleto Urbano da Natividade Tosta, escravo nagô e feitor do referido engenho. Tio Anacleto de Omolú foi autorizado pelo seu senhor a manter o terreiro após mostrar suas qualidades de "curador" na epidemia de cólera de 1860, que vitimou dezenas de escravos do plantel do engenho Natividade e das redondezas. O barracão foi construído em volta de um imponente pé de cajá consagrado ao orixá Irôco e, por isso, o terreiro é conhecido também como "candomblé do cajá". Permanece na ativa até hoje. A indicação do verbete foi de responsabilidade de Nicolau Parés e João José Reis; a referência bibliográfica é do próprio Parés, A formação do Candomblé: história e ritual da nação jeje na Bahia, (Parés, 2007: 196-97 e 209), e da dissertação de mestrado de Luiz Claudio Dias Nascimento, "Terra de macumbeiros. Redes de sociabilidades africanas na formação do candomblé jeje-nagô em Cachoeira e São Félix - Bahia” (Nascimento, 2007).

As igrejas e irmandades fundadas por africanos provavelmente surpreenderão tan to o leitor menos especializado como o historiador de ofício, em função da expressão numérica das indicações que conseguimos reunir (20 indicações): Igreja de Nossa Senhora do Rosário dos Pretos de Olinda (PE), Igreja de Nossa Senhora do Rosário dos Pretos de Recife(PE), Igreja de Nossa Senhora do Rosário dos Pretos de Igarassu (PE), Igreja de Nossa Senhora do Rosário de Lagarto (SE), Igreja de Nossa Senhora do Rosário de Laranjeiras (SE), Igreja de Nossa Senhora do Rosário dos Homens Pretos de São Cristóvão (SE), Igreja de Nossa Senhora do Rosário dos Pretos do Pelourinho (Salvador - BA), Igreja de Nossa Senhora do Rosário dos Pretos da Rua João Pereira (Salvador - BA), Igreja de Nossa Senhora do Rosário dos Homens Pretos de Cachoeira (BA), Igreja de Nossa Senhora do Rosário de Santo Amaro (BA), Igreja de Nossa Senhora do Rosário dos Pretos de Diamantina (MG), Igreja de Nossa Senhora do Rosário dos Pretos de Mariana (MG), Igreja de Nossa Senhora do Rosário de S. João Del Rei (MG), Igreja de Santa Efigênia ou de Nossa Senhora do Rosário do Alto da Cruz (Ouro Preto-MG), Igreja de Nossa Senhora do Rosário dos Pretos de Santa Luzia (Luziânia-GO), Igreja de Santo Elesbão e Santa Efigênia (Rio de Janeiro - RJ), Igreja de Nossa Senhora do Rosário e São Benedito (Rio de Janeiro - RJ), Igreja de Nossa Senhora do Rosário dos Pretos de Taubaté (SP), Igreja 
de Nossa Senhora do Rosário dos Homens Pretos de São Paulo(SP), Igreja de Nossa Senhora do Rosário e São Benedito de Florianópolis (SC).

Africanos de diversas procedências converteram-se, fundaram irmandades, participaram de festas e construíram igrejas em devoção aos santos católicos negros, como Santo Elesbão, Santa Efigênia, São Benedito e Santo António do Categeró, mas, especialmente, Nossa Senhora do Rosário. Por todo o território, ao longo do período colonial e de todo o século XIX, o catolicismo tornou-se também africano. Para além do patrimônio arquitetônico, as inúmeras igrejas pertencentes a irmandades de "Homens Pretos", como eram oficialmente chamadas, representam hoje marcos visíveis dos africanos no conjunto da população católica.

Entre as inúmeras igrejas e irmandades fundadas por africanos, destacaremos aqui a do Rosário de São João Del Rei (MG), a de Santo Elesbão e Santa Efigênia no Rio de Janeiro (RJ), e a do Rosário e São Benedito de Florianópolis (SC), por evidenciarem a variedade geográfica e a organização dos recém-chegados.

A Igreja de Nossa Senhora do Rosário de São João Del Rei foi erguida no início do século XVIII. Em 1708, foi instituída a Irmandade de Nossa Senhora do Rosário e de São Benedito dos Homens Pretos, cujos devotos se reuniam na antiga capelinha de Nossa Senhora do Pilar. Em 1719, a irmandade recebeu autorização para erguer templo próprio, o que de fato ocorreu a partir de 1720, na praça Embaixador Gastão da Cunha. Em 1753, a igreja sofreu alguns acréscimos e remodelações, adquirindo as dimensões atuais. Nos livros de entradas de irmãos do final do século XVIII e início do XIX, encontram-se registros de escravos e libertos de diversos grupos de procedência, além de crioulos: minas, angolas, congos e, principalmente, benguelas. A indicação desse local de memória foi feita por Silvia Brügger, baseada em seu estudo com Anderson Oliveira, "Os Benguelas de São João del Rei: tráfico atlântico, religiosidade e identidades étnicas, séculos XVIII e XIX” (Brügger e Oliveira, 2009).

Inaugurada em 1754, a Igreja de São Elesbão e Santa Efigênia pertence ainda hoje à irmandade devota a esses santos, que havia sido fundada um pouco antes, em 1740. Diferente da Irmandade do Rosário, foi sempre uma pequena congregação que reunia africanos vindos da Costa da Mina, os chamados negros minas. Para além do patrimônio arquitetônico, o templo representa a presença africana no conjunto da população escrava convertida ao catolicismo durante a vigência da escravidão. A igreja fica na rua da Alfândega, número 219, no Centro do Rio de Janeiro. A referência fundamental desse verbete é a obra de Mariza de Carvalho Soares, também responsável pela indicação e redação, Devotos da cor. Identidade étnica, religiosidade e escravidão no Rio de faneiro, século XVIII (Soares, 2000).

Por fim, a Igreja do Rosário e São Benedito de Florianópolis (SC) foi inicialmente uma capela da Irmandade de Nossa Senhora do Rosário dos Homens Pretos, erigida em meados do século XVIII na rua Marechal Guilherme, número 
60. A irmandade foi fundada na vila de Nossa Senhora do Desterro, atual Florianópolis, pouco antes. A partir de 1841, tomou o nome de Irmandade de Nossa Senhora do Rosário e São Benedito dos Homens Pretos. Fundada por africanos libertos e escravos, constituiu-se como a primeira associação de africanos e seus descendentes na Ilha de Santa Catarina. A igreja, que permanece com suas características arquitetônicas originais, foi construída entre 1787 e 1830. A irmandade, atualmente ativa, ainda possui seus arquivos, com documentação a partir do final do século XVIII até hoje. A indicação e a redação do verbete foram de Henrique Espada Lima, que faz parte do projeto de história pública da Universidade Federal de Santa Catarina - Santa Afro Catarina. ${ }^{11}$

Um campo expressivo da presença dos africanos, que sabíamos ser muito representativo, era a do mundo do trabalho. O trabalho e o cotidiano, no período colonial e ao longo do século XIX, foram marcados pela presença de africanos, de diferentes procedências, nas mais diversas regiões e atividades. Há registros de seu movimento nos inúmeros locais de trabalho das cidades, das minas de ouro e das fazendas. Sua atuação estendia-se pelas estradas, praças, feiras, mercados públicos e, até mesmo, a uma das poucas indústrias existentes no país, a Fábrica de Ferro Ipanema. Nesses locais de trabalho, eles criaram possibilidades de transformação da própria escravidão.

Desses locais, indicamos no Inventário: Praça do Pelourinho de Alcântara (Alcântara-MA), Beco de Catarina Mina (São Luís - MA), Árvore Baobá (Nísia Floresta - RN), Mercado da Praia da Preguiça (Salvador - BA), Ruínas das Senzalas do Engenho Freguesia (Candeias - BA), Ruínas do Engenho Vitória (Cachoeira - BA), Mina de Ouro do Chico Rei - Encardideira (Ouro Preto MG), Sítio Arqueológico do Morro de Santana (Mariana - MG), Senzala da Fazenda Santa Clara (Santa Rita de Jacutinga - MG), Chapada dos negros (Arraias - TO), Caminho do Ouro - Estrada Real (Paraty-RJ), Fazenda dos Beneditinos (Duque de Caxias - RJ), Fazenda Lordelo (Sapucaia - RJ), Fazenda e Senzala Machadinha (Quissamã - RJ), Casa de Zungu - (Rio de Janeiro - RJ), Estrada Velha São Paulo - Santos (SP), Floresta Nacional de Ipanema (Real Fábrica de Ferro) (Iperó - SP), Praça da Liberdade (São Paulo - SP), Comunidade Quilombola Guajuvira (Curiúva - PR), Invernada Paiol de Telha (Guarapuava - PR), Porto de Desterro e Mercado Público (Florianópolis - SC), Capela de Sant'Anna (Florianópolis - SC), Fazenda da Tapera da Barra do Sul (Florianópolis - SC), Sítio das Charqueadas (Pelotas - RS).

Para chamar a atenção para a presença africana em um local hoje muito distante dessa herança e legado, lembramos aqui a Praça da Liberdade, antigo Largo da Forca, na cidade de São Paulo, uma indicação de Maria Helena P. T. Machado. Segundo o verbete, a atual Praça da Liberdade já foi conhecida como Largo da Forca, por ser o onde foram supliciados muitos escravos e africanos sentenciados. Atualmente, a Igreja de Santa Cruz dos Enforcados e a Capela de Nossa Se- 
nhora dos Aflitos são representantes de um complexo cultural afro-brasileiro de religiosidade. A edificação da Igreja dos Enforcados, a partir de uma cruz e um velário, teria sido motivada pela execução do famoso soldado negro santista, cabo Francisco José das Chagas, o Chaguinhas, em 20 de setembro de 1821. Chaguinhas teria liderado uma revolta por melhores soldos para os militares nacionais na época da Independência. Seu corpo foi sepultado no cemitério de Nossa Senhora dos Aflitos, erguido em 1779, em local bem próximo ao Largo da Forca, dedicado a receber majoritariamente escravos e supliciados que não conseguissem enterramento nos adros das igrejas. No centro do cemitério ergueu-se a Capela dos Aflitos, que continua no mesmo lugar. Os terrenos do cemitério foram leiloados em 1885, tendo sido preservados apenas o Beco e a Capela dos Aflitos, que ainda hoje é um centro de romaria popular. O cemitério nunca foi escavado. ${ }^{12}$

Como não poderia ficar sem registro, os africanos também organizaram muitas revoltas e quilombos no Brasil. E se Palmares foi o maior símbolo da resistência contra a escravidão na sociedade colonial, variadas foram as formas de luta direta e contestação do sistema escravista. Fugas, organização de quilombos e revoltas aconteceram em qualquer local onde houvesse escravidão. Mesmo que não tenham tido êxito completo, esses movimentos transformaram a dominação e deixaram notícias das ações e caminhos dos africanos rumo à liberdade ao longo do período colonial e do século XIX. Entre as revoltas, fugas e quilombos que inventariamos encontram-se: Negro Cosme/ Balaiada (Vale do Itapecuru-MA), Quilombo do Catucá/Malunguinho (Recife - PE), Quilombo de Palmares (União de Palmares - AL), Quilombo do Buraco do Tatu (Salvador - BA), Engenho Santana (Ilhéus - BA), Bairro de Itapoan (Salvador - BA), Ladeira da Praça (Salvador - BA), Campo da Pólvora (Salvador - BA), Largo do Pelourinho (Salvador-BA), Carrancas (Cruzília-MG), Sítio Histórico do Patrimônio Kalunga (Cavalcanti, Monte Alegre e Teresina-GO), Manoel Congo (Vassouras/Paty do Alferes - RJ) e Quilombo Maria Conga (Magé - RJ).

A responsabilidade pelo verbete de uma das maiores revoltas ficou com João José Reis. A Revolta dos Malês, considerada a mais importante insurreição de escravos urbanos nas Américas, teve início na madrugada do dia 24 para 25 de janeiro de 1835 em Salvador ao pé da Ladeira da Praça, em frente ao atual Quartel General do Corpo de Bombeiros, na casa de dois libertos nagôs. Foi organizada por africanos iorubás, chamados nagôs no Brasil, e adeptos do Islã, os malês; mas contou com a participação de negros não muçulmanos, escravos e libertos, e alguns de outras nações que não os nagôs. Estima-se que os rebeldes tenham sido em torno de 600 . Cerca de 50 morreram em combate e nove pessoas foram mortas por eles. A referência é do próprio livro de João José Reis, Rebelião escrava no Brasil: A história do levante dos Malês, 1835 (Reis, 2003). 
Por fim, a presença dos africanos no Brasil contemporâneo pode ser identificada na vivência de um patrimônio cultural expresso em memórias, músicas, versos, cantos, danças e perfomances, e associado aos marcos de sua História. A valorização recente do patrimônio imaterial por políticas públicas culturais tem proporcionado maior visibilidade à herança africana no Brasil, assim como maior reconhecimento do passado escravo e negro. O patrimônio imaterial africano é reconstruído por diversas comunidades e torna-se bandeira de luta por direitos e afirmação da identidade negra, como vimos.

Nesta categoria, inventariamos o Tambor de Crioula (MA), Maracatu (Recife - PE), Samba de roda (Recôncavo da Bahia), Capoeira (Rio de Janeiro/Salvador - RJ/BA), Congado (MG, RJ, SP), Ticumbi (São Mateus e Conceição da Barra - ES), Jongo (RJ, SP, MG, ES) e Comunidades Remanescentes de Quilombo (em todo Brasil).

A decisão de reunir todas as comunidade de Remanescentes de Quilombo num único inventário justifica-se pelo número expressivo dessas comunidades e pela nossa dificuldade em selecionar algumas que fossem representativas. Por outro lado, nem todas possuem estudos aprofundados sobre suas histórias. Até o ano de 2012, a Fundação Cultural Palmares certificou, desde a Constituição de 1988, mais de 1.500 comunidades quilombolas, consideradas hoje patrimônio cultural e imaterial do Brasil.

Essas comunidades, formadas por descendentes das últimas gerações de africanos trazidos como escravos para o Brasil, lutam pela titulação de territórios ocupados coletivamente. Seus direitos estão garantidos pela Constituição Federal de 1988, através do artigo 68 do Ato das Disposições Constitucionais Transitórias, e pelo Decreto 4887, de 2003. Este último regulamentou “a caracterização dos remanescentes das comunidades dos quilombos" a partir da "autodefinição da própria comunidade", entendendo-as como "grupos étnico-raciais, com trajetória histórica própria, dotados de relações territoriais específicas, com presunção de ancestralidade negra relacionada com a resistência à opressão histórica sofrida". A memória da escravidão, do tráfico, da África e do pós-abolição fortalece as reivindicações de garantia do território. Daniela Yabeta foi a responsável pela redação do verbete e as referências podem ser buscadas em Eliane Cantarino O'Dwyer, “Terras de Quilombo: identidade étnica e os caminhos do reconhecimento" (O’Dwyer, 2008: 43-58).

As comunidades quilombolas de São José da Serra, em Valença (RJ) e do Bracuí, no sul fluminense, bem como o Centro de Referência do Jongo de Pinhei$\mathrm{ral}(\mathrm{RJ})$, com os quais temos trabalhado mais diretamente, representam exemplarmente o movimento de diversos grupos descendentes de escravizados, em várias partes do mundo e no Brasil, que reivindicam políticas de reparação baseados na memória de experiências de violência e opressão historicamente vividas e que são 
vistas como contrárias ao que estabelecem as convenções universais de direitos humanos (Mattos, 2006; Mattos e Abreu, 2011: 147-160).

Além de quilombolas, essas comunidades são guardiãs do jongo, patrimônio cultural imaterial afro-brasileiro, também listado no inventário. Silenciados e marginalizados por muito tempo, em função de suas práticas culturais vistas como folclóricas, atrasadas ou em vias de desaparecimento, os jongueiros do Sudeste reivindicavam a defesa do seu patrimônio e sua inscrição entre os bens considerados Patrimônios da Nação brasileira (Abreu e Mattos, 2007: 69-108). ${ }^{13}$ Acionaram, como os quilombolas, dispositivos legais da Constituição que reconheciam, também com apoio da Unesco, o registro, inventário e proteção de seus patrimônios imateriais populares e negros (Abreu, 2007). ${ }^{14}$

Por fim, a memória da fase ilegal do comércio negreiro está presente na tradição oral dessas comunidades, dialogando com a documentação escrita e arqueológica para renovar a pesquisa histórica sobre o tema (Mattos, 2013). Essas reivindicações envolvem, portanto, não só direitos a reparações materiais e simbólicas, como também o que se convencionou chamar de "dever de memória" (Heymann e Arruti, 2012). Ou seja, a luta para que determinados acontecimentos como as histórias do tráfico e da escravização não sejam esquecidos, para que continuem presentes na memória de grupos e nações e para que sejam registrados na memória pública do país.

A realização do Inventário dos Lugares de Memória do Tráfico Atlântico de Escravos e da História dos Africanos Escravizados no Brasil insere-se exatamente nesse contexto de lutas e de reavaliação do legado e dos direitos dos afrodescendentes no Brasil.

Notas

1. Disponível em http://www.labhoi. uff.br/node/1507 (acesso em 5 de setembro de 2014).

2. Disponível em http://www.labhoi. uff.br/escravodao (acesso em 5 de setembro de 2014).

3. Divulgamos também pesquisas e reflexões sobre memórias do cativeiro e os significados do passado escravista e de nossa própria disciplina para a im- plantação de políticas públicas de combate ao racismo, nos campos educacional e cultural, no blog http://conversadehis toriadoras.com/ (acesso em 5 de setembro de 2014).

4. Disponível emwww.labhoi.uff.br/ acervo (acesso em 5 de setembro de 2014).

5. Disponível em http://www.unesco.org/ new/en/culture/themes/dialogue/the-slav e-route/ (acesso em 5 de setembro de 2014). 
6. Disponível em http://www.palmares. gov.br/rotadoescravo/ (acesso em 5 de setembro de 2014).

7. Para mais informações sobre essa luta pelo reconhecimento de comunidades quilombolas e jongueiras no Rio de Janeiro, ver os 4 filmes da coleção Passados Presentes, produzidos por Mattos e Abreu (2011b) http://www.labhoi.uff.br/pas sadospresentes/filmes_passados.php) e o site do pontão de cultura do jongo e do caxambu http://www.pontaojongo.uff.br/ (acessos em 5 de setembro de 2014).

8. Pesquisas de Thiago Campos Pessoa Lourenço, Daniela Yabeta, Nilma Teixeira Accioli e Camilla Agostini.

9. Professores e pesquisadores que apoiaram o projeto: Adriana Pereira Campos; Agenor Sarraf Pacheco; Alexandre Almir; Alisson Eugênio; Ana Carolina Prado; Ana dos Anjos; Ane Luise S. M. Santos; Andrea Ferreira Delgado; Antonio Cesar Caldas Pinheiro; Beatriz Gois Dantas; Beatriz Loner; Beatriz Mamigonian; Camila Agostini; Carolina Martins; Carolina Vianna Dantas; Claudia Damasceno Fonseca; Claudio Honorato; Cristina Wissenbach; Enidelce Bertin; Fábia Barbosa Ribeiro; Fabiane Popinigis; Flávio Gomes; Giovana Xavier, Henrique Espada Lima; Isabel Guillen; Jaime Rodrigues; Janira Sodré Miranda; João José Reis; Juciene Apolinário; Juliana Farias; Keila Grinberg; Lopes da Fonseca; Luis Nicolau Pares; Luiz Geraldo Silva; Magno Francisco de Jesus Santos; Marcio Soares; Marcus Carvalho; Maria Antonieta Antonacci; Maria Helena P.T. Machado; Lisa Earl Castillo; Maria Loiola; Maria do Carmo Russo; Maristela Pinho da Silva; Mariana Bracks Fonseca, Mathias Assunção; Mundinha Araujo; Nicolau Parés; Nilma Acciole; Paulo R. S. Moreira; Rafael Sanzio; Rafael Soares de Oliveira; Regina Helena de Faria; Ricardo Moreno; Rodrigo Weimer; Sandro Silva; Sarah Amaral; Sérgio
Ferretti; Silvia Brügger; Solange Barbosa; Suzana Barbosa; Thiago Campos; Urano de Cerqueira Andrade; Valéria Gomes Costa; Victor Hugo Cardoso; Vinicius P. Oliveira; Walter Luiz Carneiro Mattos Pereira; Wlamyra Albuquerque.

10. Esta metodologia de trabalho, que articula narrativas temáticas, construídas a partir da pesquisa em arquivos e bibliotecas, e da produção historiográfica atualizada sobre a história do Brasil, com roteiros de visita sobre a história dos africanos e afrodescendentes em Santa Catarina, é desenvolvida pelo projeto Santa Afro Catarina, coordenado por Andréa Ferreira Delgado e Beatriz Mamigonian. Ver http:// www.santaafrocatarina.blog spot.com.br/ (acesso em 5 de setembro de 2014).

11. Programa de Educação Patrimonial sobre a presença de africanos e afrodescendentes em Santa Catarina. Roteiro Devoção ao Rosário e Festa de africanos na Ilha. Disponível em: http://www.santaafrocata rina.blogspot.com.br/ (acesso em 5 de setembro de 2014).

12. Como referências bibliográficas, Maria Helena Machado destacou: Amaral, Antonio Barreto do, Dicionário de História de São Paulo. São Paulo: Governo do Estado de São Paulo, 1980, pp. 109, 125 e 230; e Vilhena, Maria Angela, "Os mortos estão vivos: traços da religiosidade brasileira", Revista de Estudos da Religião (REVER), n. 3, 2004, pp. 103-131.

13. Como exemplos da organização dos jongueiros e da defesa de seu patrimônio, destacam-se o Pontão de Cultura do Jongo e do Caxambu http://www.pontaojongo. uff.br/ e o Centro de Referência de Estudo Afro sul fluminense (CREASF), sediado em Pinheiral (RJ), http://mapadecultu ra.rj.gov.br/manchete/centro-de-referenci a-de-estudo-afro-do-sul-fluminense

14. Ver decreto n. 3.551, em 4 de agosto de 2000. 
Referências bibliográficas

ABREU, Martha. Cultura imaterial e patrimônio histórico nacional. In: ABREU, Martha; SOIHET, Rachel \& GONTIJO, Rebeca (orgs.). Cultura política e leituras do passado: historiografia e ensino de história. Rio de Janeiro: Nova Fronteira/Faperj, 2007.

\& MATTOS, Hebe. Jongo, registros de uma história. In: LARA, Silvia H. \& PACHECO, Gustavo (orgs.). Memória do jongo. As gravações históricas de Stanley Stein. Vassouras, 1949. Campinas/Rio de Janeiro: Cecult/Folha Seca, 2007.

ALENCASTRO, Luiz Felipe. Parecer sobre a arguição de descumprimento de preceito fundamental, ADPF/186, apresentada ao Supremo Tribunal Federal, 2010. Disponível em: http://www.stf.jus.br/arqui vo/cms/processoAudienciaPublicaAcaoAfi rmativa/anexo/stf_alencastro_definitivo_a udiencia publica.doc (acesso em 6 de setembro de 2014).

ARAUJO, Ana Lucia. Public memory of slavary: victims and perpetrators in the South Atlantic. Amhers, NY: Cambria Press, 2010.

BRÜGGER, Silvia M. J. \& OLIVEIRA, Anderson J. M. de. Os benguelas de São João del Rei: tráfico atlântico, religiosidade e identidades étnicas (séculos XVIII e XIX). Revista Tempo, vol. 13, n. 26, 2009.

CARVALHO, Marcus Joaquim Maciel de. A repressão ao tráfico atlântico de escravos e a disputa partidária nas províncias: os ataques aos desembarques em Pernambuco durante o governo praieiro, 1845-1848. Tempo. Revista do Departamento de História da UFF, v. 27, 2009, p. 151-167.

CHALHOUB, Sidney. A força da escravidão. Ilegalidade e costume no Brasil oitocentista. São Paulo: Companhia das Letras, 2012.
DANTAS, Beatriz Góes. Vovó Nagô e Papai Branco: usos e abusos da África no Brasil. Rio de Janeiro: Graal, 1988.

HEYMANN, Luciana \& ARRUTI, Mauricio. Memória e reconhecimento: notas sobre as disputas contemporâneas pela gestão da memória na França e no Brasil. In: GONCALVES, M. A.; ROCHA, H.; REZNIK, L. \& MONTEIRO, A. M. (orgs.). Qual o valor da História hoje? Rio de Janeiro: Editora FGV, 2012.

HONORATO, Claudio de Paula. Valongo: o mercado de escravos do Rio de Janeiro, 1758 a 1831. Dissertação de mestrado, PPGH/UFF, 2008.

MAMIGONIAN, Beatriz G. O direito de ser africano livre: os escravos e as interpretações da Lei de 1831. In: LARA, Silvia \& MENDONÇA, Joseli M. N. (orgs.). História e Direito, jogos de encontros e transdisciplinaridade. Rio de Janeiro: Renavan, 2007.

MATTOS, Hebe. Políticas de reparação e identidade coletiva no mundo rural: Antonio Nascimento Fernandes e o quilombo São José. Estudos Históricos, Rio de Janeiro, n.37, 2006.

(org.). Diáspora negra e lugares de memória. A história oculta das propriedades voltadas para o tráfico clandestino de escravos no Brasil Imperial. Niterói: EDUFF, 2013.

\& ABREU, Martha. Remanescentes das comunidades dos quilombos: memória do cativeiro, patrimônio cultural e direito à reparação. In: ASSUNÇÃO, Matthias Röhrig (org.). Iberoamericana: América Latina - Espanha - Portugal: revista do Ibero-Amerikanisches Institut, Berlim, ano 11, n. 42, 2011a, p. 147-160.

$\&$ - Passados presentes: memória negra no sul fluminense. Niterói: 
Labhoi/UFF, 2011b. Disponível em: http://www.labhoi.uff.br (acesso em 5 de setembro de 2014).

NASCIMENTO, Luiz Claudio Dias. "Terra de macumbeiros". Redes de sociabilidades africanas na formação do candomblé jeje-nagô em Cachoeira e São Félix - Bahia. Dissertação de mestrado. Programa de Pós-Graduação Multidisciplinar em Estudos Étnicos e Africanos. Universidade Federal da Bahia (UFBA). Salvador, 2007.

NORA, Pierre. Entre mémoire et histoire. La problématique des lieux. In: Les lieux de mémoire. Paris: Gallilmard, 1986.

O'DWYER, Eliane Cantarino. Terras de quilombo: identidade étnica e os caminhos do reconhecimento. Tomo (UFS), v. 11, 2008, p. 43-58.

PARES, Nicolau. A formação do candomblé: história e ritual da nação jeje na Bahia. Campinas: Ed. da Unicamp, 2007.

PINEAU, Marisa (org). Huellas y legados de la esclavitud em las Americas. Projeto Unesco La Ruta Del Escravo. Saenz Peña: Universidad Nacional de Tres de Febrero, 2012.

REIS, João José. Rebelião escrava no Brasil: $A$ história do levante dos Malês, 1835. $2^{\mathrm{a}}$ ed. São Paulo: Companhia das Letras, 2003.

SOARES, Mariza. Devotos da cor. Identidade étnica, religiosidade e escravidão no Rio de Faneiro, século XVIII. Rio de Janeiro: Civilização Brasileira, 2000.

\title{
Resumo
}

$\mathrm{O}$ artigo tem como objetivo principal apresentar os desafios enfrentados na construção e organização do "Inventário dos Lugares de Memória do Tráfico Atlântico de Escravos e da História dos Africanos Escravizados no Brasil”, trabalho que faz parte do Projeto Rota do Escravo, da Unesco.

A lista de 100 lugares de memória foi produzida em articulação com diversos especialistas no tema, com base em pesquisas recentes sobre a história social do tráfico e da escravidão no Brasil, e em estreito diálogo com a reavaliação do legado e dos direitos dos afrodescendentes no Brasil.

Palavras-chave: história pública; lugares de memória; escravidão; tráfico atlântico.

\begin{abstract}
The article describes the main challenges faced in the effort to build and organize the "Inventory of Places of Memory of the Atlantic Slave Trade and of the History of Enslaved Africans in Brazil", which is part of the Unesco's Slave Route Project. The list of 100 places of memory of the inventory was made thanks to the collaboration of many researchers interested in the social history of slavery and the slave trade to Brazil. The work was also developed in close dialogue with the contemporary discussions about Afro-Brazilians' heritage and rights.

Keywords: public history; places of memory; slavery; Atlantic slave trade.
\end{abstract}




\section{Résumé}

Larticle présente les défis affrontés pour construire et organiser «L'Inventaire des Lieux de Mémoire de la Traite Négrière Atlantique et de l'Histoire des Esclaves Africains au Brésil», qui fait partie du projet de l'Unesco Route de l'Esclave. La liste de 100 lieux de mémoire a été faite em collaboration avec plusieurs experts en la matière, sur la base de recherches récentes sur l'histoire sociale de la traite négrière et de l'esclavage au Brésil, et en dialogue étroit avec les discussions sur l'héritage et les droits des afro-descendants au Brésil.

Mots-clés:histoire publique; lieux de mémoire; esclavage; traite négrière. 